\title{
Study of fuel economy and emissions for converted plug-in parallel hybrid electric vehicles versus conventional diesel vehicles on standard driving cycles
}

\author{
Pritam Keshavdas Gujarathi ${ }^{1 * *}$, Varsha A. Shah ${ }^{1}$ and Makarand M. Lokhande ${ }^{2}$ \\ ${ }^{1}$ Department of Electrical Engineering, Sardar Vallabhbhai National Institute of Technology, Surat 395 007 , India \\ ${ }^{2}$ Department of Electrical Engineering, Visvesvaraya National Institute of Technology, Nagpur 440010 , India
}

Electric and plug-in hybrid electric vehicles (PHEVs) are gaining attention nowadays due to their environmental impact. However, there is less attention in terms of conversion of conventional vehicles (CVs) into PHEVs to address the environmental impact of present vehicles running on the road. This study examines fuel economy and emissions of parallel converted PHEV (CPHEV) and compares them with CV for urban dynamometer driving schedule and West Virginia suburban driving schedule. The parameters of conventional $2 \mathrm{~L}$ diesel engine car and its converted version of a PHEV are used for the study. Indepth analysis of a CV and CPHEV has been done. ADVISOR software is used in linking with MATLAB as a simulation tool. The results show a significant reduction in emissions and fuel consumption of CPHEV compared to $\mathrm{CV}$, which motivates for conversion of CVs into PHEVs.

Keywords: Converted plug-in hybrid electric vehicle, driving cycle, emissions, electric vehicles, fuel consumption.

ELECTRIC vehicles have proven their existence. Registration of electric cars hit a new record in 2016, with over 750,000 sales worldwide ${ }^{1}$. The share of the transport sector regarding global energy-related $\mathrm{CO}_{2}$ emissions is $23 \%$. Emissions increased by $2.5 \%$ annually between 2010 and 2015. Petroleum-based liquid fuels currently account for most of the global transportation energy consumption and will continue to do so through 2040 (ref. 2; Supplementary Figure 1). Due to this, emissions caused by present vehicles on the road do not comply with the norms and around three million deaths are attributed worldwide every year due to ambient air pollution ${ }^{3}$. Hence the conversion of conventional vehicles (CVs) to plug-in hybrid electric vehicles (PHEVs) is one of the hopeful solutions to mitigate emissions caused by present vehicles running on the road. However, according to the literature, there is less research on converted plug-in

\footnotetext{
*For correspondence. (e-mail: pritamgujarathi@ rediffmail.com)
}

hybrid electric vehicles (CPHEVs). Most of the studies are on conversion aspect and energy management strategy with stress on fuel economy ${ }^{4-15}$. Both fuel economy and emissions are not considered. Hence there is a need to analyse the conversion of $\mathrm{CV}$ into PHEVs in terms of both emissions and fuel economy.

This article deals with an in-depth study of a CV and CPHEV. The performance analysis of components is detailed along with fuel economy and all emissions. ADVISOR software is used with MATLAB as a simulation tool. ADVISOR, NREL's ADvanced VehIcle SimulatOR is a set of model, data and script text files for use with MATLAB and Simulink. It is designed for rapid analysis of the performance and fuel economy of conventional, electric and hybrid vehicles.

\section{Vehicle parameters}

Table 1 provides specifications of the vehicle used in this study.

Table 1. CV and CPHEV specifications

\begin{tabular}{ll}
\hline CV specification and parameters & \\
Weight & $1200 \mathrm{~kg}$ \\
Engine type & Four-cylinder turbo intercooled \\
Displacement & $2000 \mathrm{cc}$ \\
Fuel type & Diesel \\
Maximum power & $70 \mathrm{bhp} @ 4500 \mathrm{RPM}$ \\
Maximum torque & $135 \mathrm{Nm} @ 3000 \mathrm{RPM}$ \\
Frontal area & $2.12 \mathrm{~m}^{2}$ \\
Gear ratio & $3.42: 1.95: 1.13: 0.74: 0.636$ \\
Differential ratio & $3.73: 1$ \\
Radius of tire & $0.2876 \mathrm{~m}$ \\
Frontal area $\left(F_{\mathrm{A}}\right)$ & $2.12 \mathrm{~m}^{2}$ \\
CPHEV specification & \\
Base speed & $60 \mathrm{~km} / \mathrm{h}$ \\
Range/charge & $60 \mathrm{~km}$ \\
Acceleration & $1.667 \mathrm{~m} / \mathrm{s}^{2}(0-60 \mathrm{~km} / \mathrm{h})$ \\
Battery capacity & $22.6 \mathrm{kWh}, 192 \mathrm{~V}$ \\
Battery type & Lead acid \\
Motor capacity & $15.76 \mathrm{~kW}$ \\
Motor & Three-phase induction motor \\
\hline
\end{tabular}


Supplementary Figures 2-4 show the performance of a fuel converter, i.e. diesel engine. These figures also show contour maps of engine efficiency and specific fuel consumption for torque versus speed characteristics of a diesel engine car generated using data obtained from ref. 16.

It can be seen that maximum efficiency of an internal combustion (IC) engine is $32 \%$. Efficiency is above $30 \%$ for high torque and mid speed range (Supplementary Figure 2). However, at lower torque, the efficiency is very low. Also, specific fuel consumption is low during high torque operations and high for lower torque (Supplementary Figure 2).

Supplementary Figures 3 and 4 show the contours of emissions of hydrocarbon (HC), carbon monoxide (CO), nitrogen oxides $\left(\mathrm{NO}_{x}\right)$ and particulate matter $(\mathrm{PM})$.

It can be seen from Supplementary Figure $3 a$ and $b$ that $\mathrm{CO}$ is less at higher torque and lower speed, whereas $\mathrm{HC}$ is less at lower speed and lower torque.

Supplementary Figure 4 shows that PM is less for all values of torque and for lower speed, whereas $\mathrm{NO}_{x}$ is less at lower speed and lower torque.

In short, all objectives are conflicting in nature; hence optimizing this is a challenging and critical task. In this study, fuzzy logic is used to optimize all emissions with fuel consumption. Figures 1 and 2 show the driving cycles used for testing the performance.

The urban dynamometer driving schedule (UDDS) cycle shown in Figure 1 simulates an urban route of $11.99 \mathrm{~km}$ with frequent stops ${ }^{16}$. The maximum speed is $91.25 \mathrm{~km} / \mathrm{h}$ and average speed is $31.5 \mathrm{~km} / \mathrm{h}$ with an idle
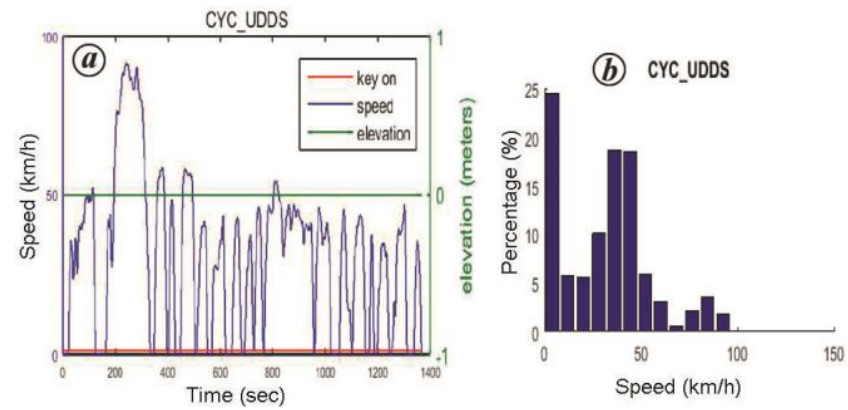

Figure 1. $\boldsymbol{a}$, USSD driving cycle. $\boldsymbol{b}, \%$ Speed distribution.
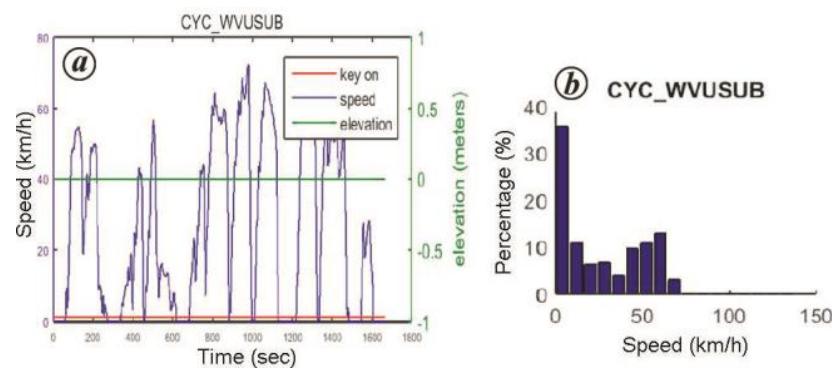

Figure 2. $\boldsymbol{a}$, WVSUB driving cycle. $\boldsymbol{b}$, \% Speed distribution. time of $259 \mathrm{sec}$. The maximum acceleration and deceleration are 1.48 and $-1.48 \mathrm{~m} \mathrm{~s}^{-2}$ respectively (Table 2 ).

Figure 2 shows the West Virginia suburban driving schedule (WVSUB) driving cycle which simulates an urban-suburban route of $11.97 \mathrm{~km}$. The maximum speed is $72.1 \mathrm{~km} / \mathrm{h}$ and average speed is $25.87 \mathrm{~km} / \mathrm{h}$ with six stops. The maximum value of acceleration and deceleration are 1.29 and $2.16 \mathrm{~m} \mathrm{~s}^{-2}$ respectively (Table 3 ).

\section{Simulation of CV in ADVISOR}

Supplementary Figure 5 shows the backward model of a conventional diesel vehicle.

The driving cycle can be given as input, which can be individual or a combination of standard driving patterns. Using the driving cycle, the vehicle dynamics estimates the required values of torque for the input speed and checks the achievability using actual speed at the wheels, which are taken from the output of the next block as the input of the previous block. Wheels are connected to two axles; hence torque and speed required and availability are calculated from the output of the next block, i.e. previous values, continued to the differential, gearbox which is connected to the clutch. The clutch has three inputs; the central input comes from the controller where all controls are available like gear selection logic, clutch state, engine control logic, etc., which gives signal to the

Table 2. USSD driving cycle details

\begin{tabular}{ll}
\hline Parameter & \multicolumn{1}{c}{ Values } \\
\hline Time & $1369 \mathrm{sec}$ \\
Distance & $11.99 \mathrm{~km}$ \\
Maximum speed & $91.25 \mathrm{~km} / \mathrm{h}$ \\
Average speed & $31.51 \mathrm{~km} / \mathrm{h}$ \\
Maximum acceleration & $1.48 \mathrm{~m} / \mathrm{s}^{2}$ \\
Maximum deceleration & $-1.48 \mathrm{~m} / \mathrm{s}^{2}$ \\
Average acceleration & $0.5 \mathrm{~m} / \mathrm{s}^{2}$ \\
Average deceleration & $-0.58 \mathrm{~m} / \mathrm{s}^{2}$ \\
Idle time & $259 \mathrm{sec}$ \\
No. of stops & 17 \\
Grade & $0 \%$ \\
\hline
\end{tabular}

Table 3. WVUSUB driving cycle details

\begin{tabular}{ll}
\hline Parameter & \multicolumn{1}{c}{ Values } \\
\hline Time & $1665 \mathrm{sec}$ \\
Distance & $11.97 \mathrm{~km}$ \\
Maximum speed & $72.1 \mathrm{~km} / \mathrm{h}$ \\
Average speed & $25.87 \mathrm{~km} / \mathrm{h}$ \\
Maximum acceleration & $1.29 \mathrm{~m} / \mathrm{s}^{2}$ \\
Maximum deceleration & $-2.16 \mathrm{~m} / \mathrm{s}^{2}$ \\
Average acceleration & $0.33 \mathrm{~m} / \mathrm{s}^{2}$ \\
Average deceleration & $-0.42 \mathrm{~m} / \mathrm{s}^{2}$ \\
Idle time & $420 \mathrm{sec}$ \\
No. of stops & 9 \\
Grade & $0 \%$ \\
\hline
\end{tabular}




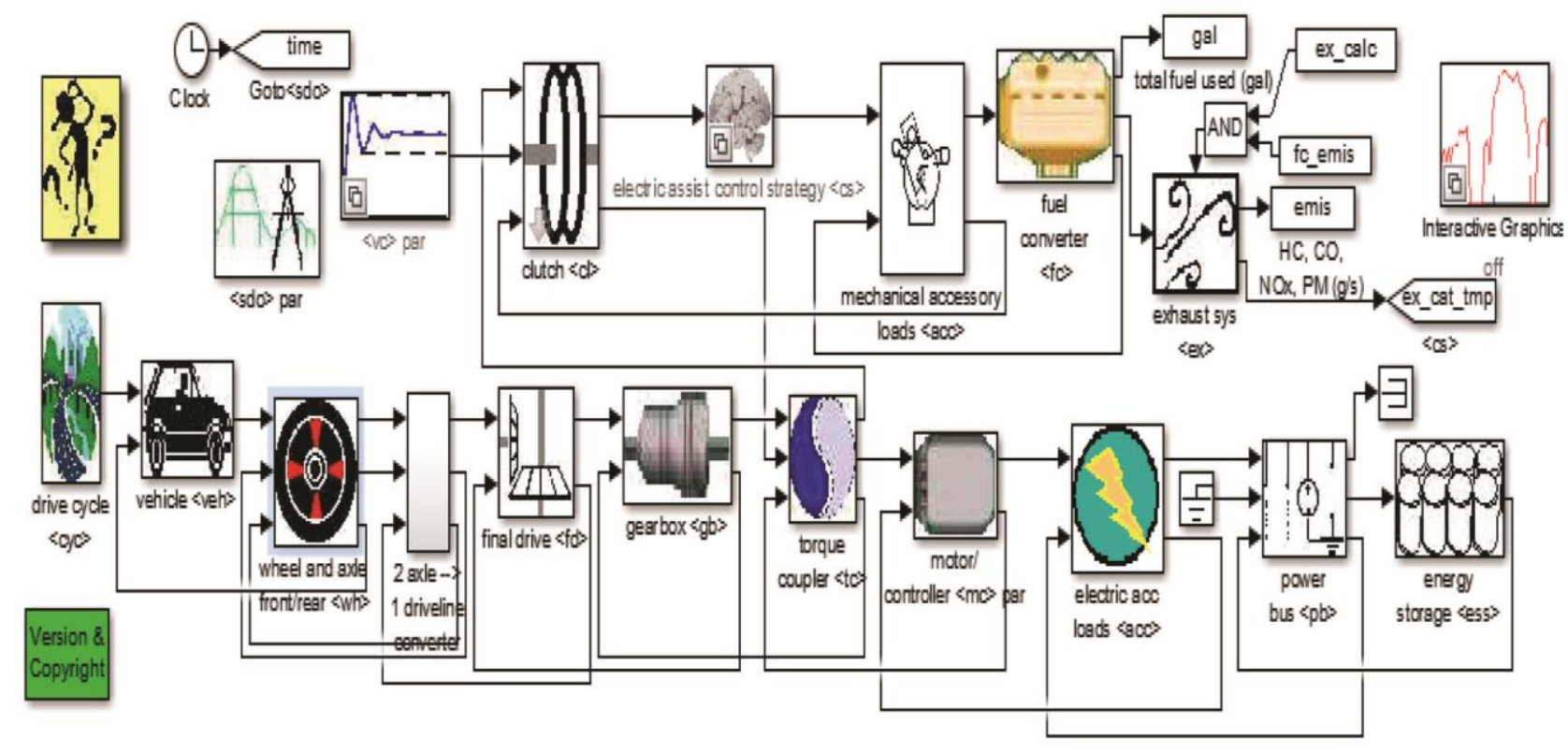

Figure 3. CPHEV in ADVISOR.
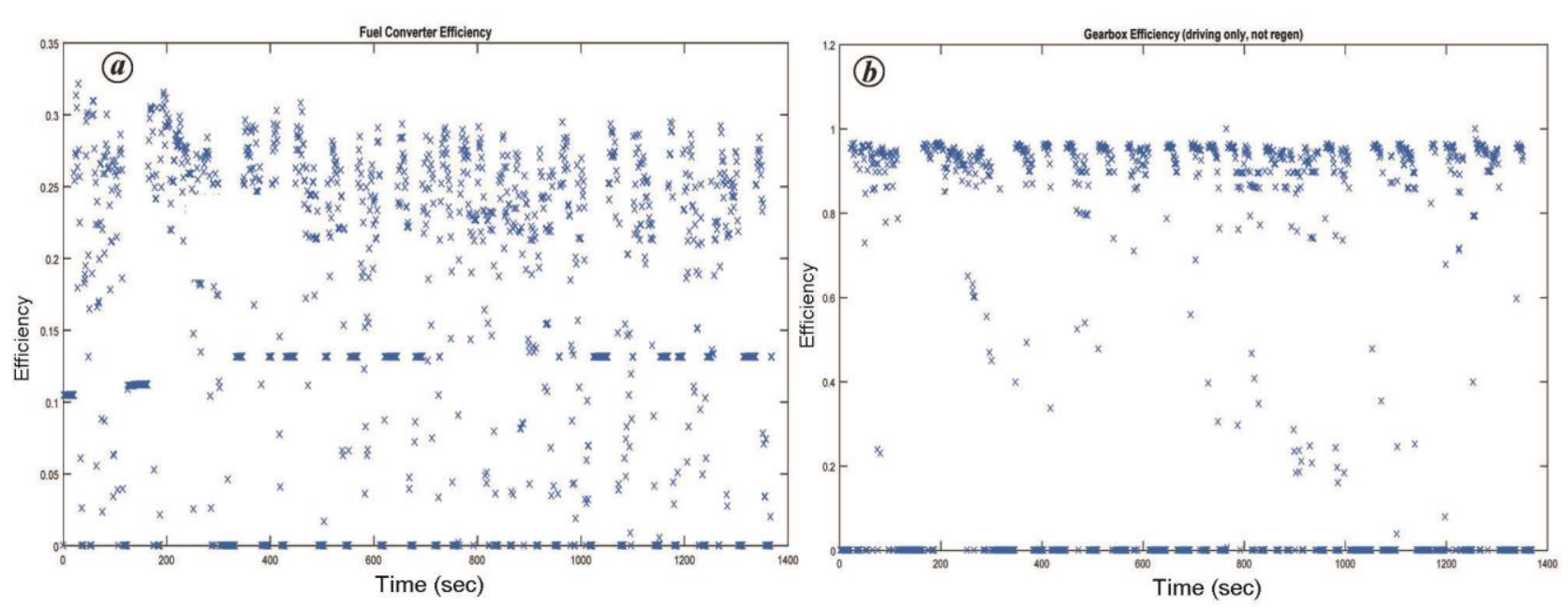

Figure 4. $\boldsymbol{a}$, Fuel converter efficiency. $\boldsymbol{b}$, Gearbox efficiency.

clutch to request for the required torque and speed for mechanical accessory load. The second input is the output of the next block which is used to calculate torque and speed achieved with the previous values. The command is given to the engine controller from the fuel converter to increase speed and torque. In the fuel converter, emission and fuel use equations are simulated using basic equations. Hence, fuel consumption and emission details can be obtained from the available stored data. The data specified are used and performance is studied for $\mathrm{CV}$ as well as CPHEV. Supplementary Figures 6 and 7 show the results generated for CPHEV tested for the UDDS cycle.

It can be seen from Supplementary Figure $6 a$ that efficiency at which an IC engine is operated is distributed with all values for the UDDS driving cycle. Supplementary
Figure $6 c$ shows the operating points with efficiency contour. It can be observed that the IC engine is operating at very low values of efficiency mostly in the lower torque and speed region. The operating points for the UDDS cycle are seen for torque mostly less than $80 \mathrm{Nm}$ (green) at low values of speed (less than $2000 \mathrm{rpm}$ of the engine). The gearbox operates with high efficiency (Supplementary Figure 6b). Supplementary Figure 7 shows the speed, torque, brake torque and wheel slip of the vehicle obtained for the UDDS cycle.

It can be seen that speed is followed by a vehicle with around $1-1.8 \%$ of slip. Supplementary Figure 7 shows the corresponding value of torque and negative brake torque available for regeneration. In addition, torque available from regeneration during braking can be seen from brake 

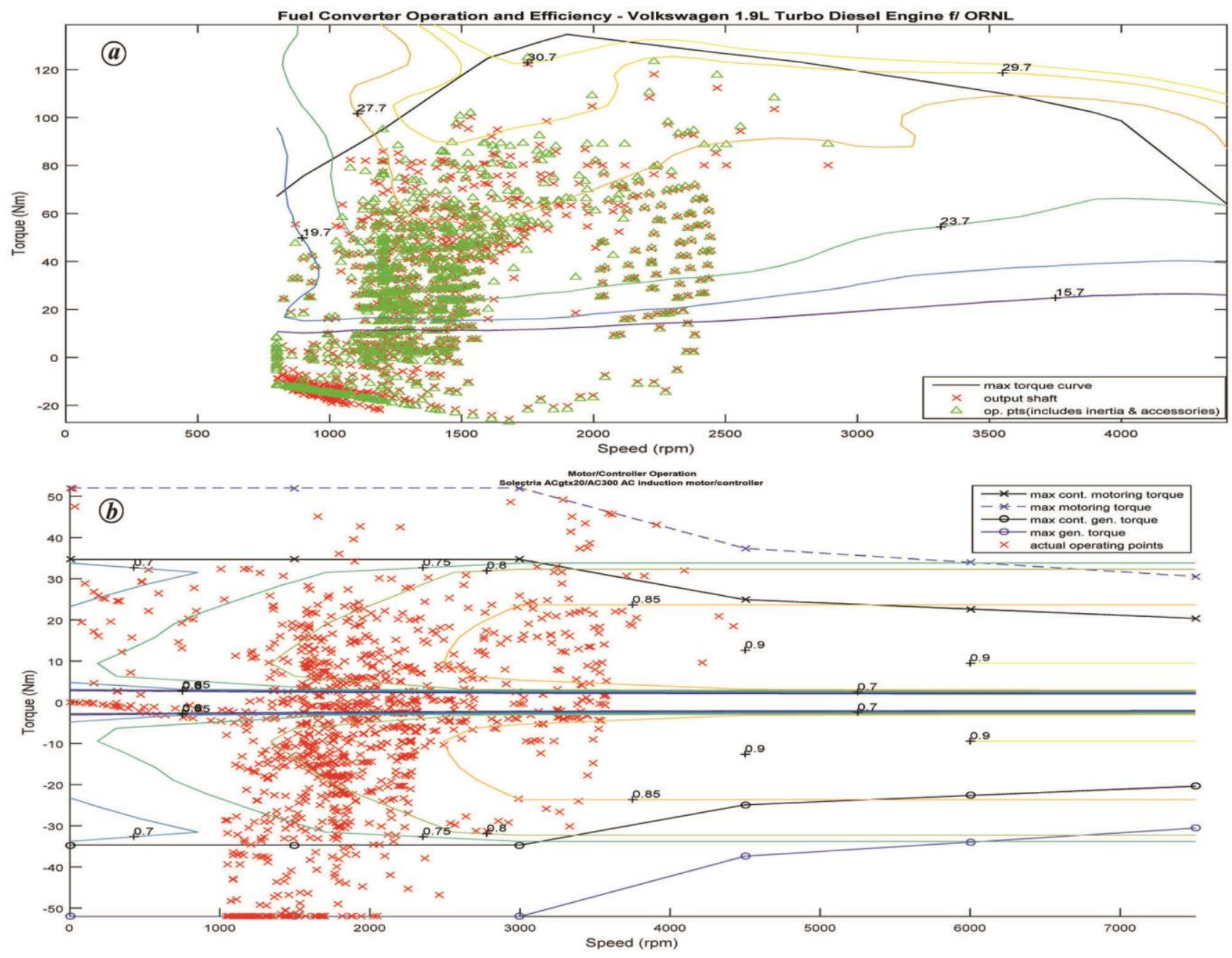

Figure 5. $\boldsymbol{a}$, Operating points of engine. $\boldsymbol{b}$, Operating points of motor with efficiency contour.

Table 4. Fuel consumption and emissions $-\mathrm{CV}$

\begin{tabular}{|c|c|c|c|c|c|}
\hline \multirow[b]{2}{*}{ Driving cycle } & \multirow{2}{*}{$\begin{array}{l}\text { Fuel consumption } \\
\text { litre } / 100 \mathrm{~km}\end{array}$} & \multicolumn{4}{|c|}{ Emissions (g/km) } \\
\hline & & $\mathrm{HC}$ & $\mathrm{CO}$ & $\mathrm{NO}_{x}$ & PM \\
\hline UDDS & 5.1 & 0.318 & 0.32 & 0.454 & 0.033 \\
\hline WVSUB & 5.2 & 0.222 & 0.532 & 0.434 & 0.032 \\
\hline
\end{tabular}

torque, e.g. before $400 \mathrm{sec}$, deceleration of the vehicle resulted in the availability of regenerative torque of around $-100 \mathrm{Nm}$ for a short time. During braking near $120 \mathrm{sec}$, the braking torque of around $-30 \mathrm{Nm}$ is available (Supplementary Figure 7). Table 4 shows the fuel consumption and emissions for the UDDS and WVSUB driving cycles.

Fuel consumption is almost the same, i.e. 5.1 and 5.2 litre/100 $\mathrm{km}$ for the UDDS and WVSUB cycles respectively. The values of $\mathrm{HC}$ and $\mathrm{NO}_{x}$ are higher in UDDS and CO is less compared to WVSUB. The value of PM is nearly the same for both cycles.

\section{Simulation of CPHEV in ADVISOR}

Figure 3 depicts the simulation of CPHEV. It can be seen that an extra component of the electrical drivetrain is connected through the torque coupler. The designed parameters of electric drivetrain are considered for study. The lead acid battery is used as energy storage device and three phase induction motor is preferred for driving the wheels. Fuzzy logic control algorithm is employed for torque distribution in hybrid mode for controlling emissions.

$\underline{\text { Supplementary Figure } 8}$ depicts a motor efficiency map at different values of speed and torque. The efficiency 
RESEARCH ARTICLES
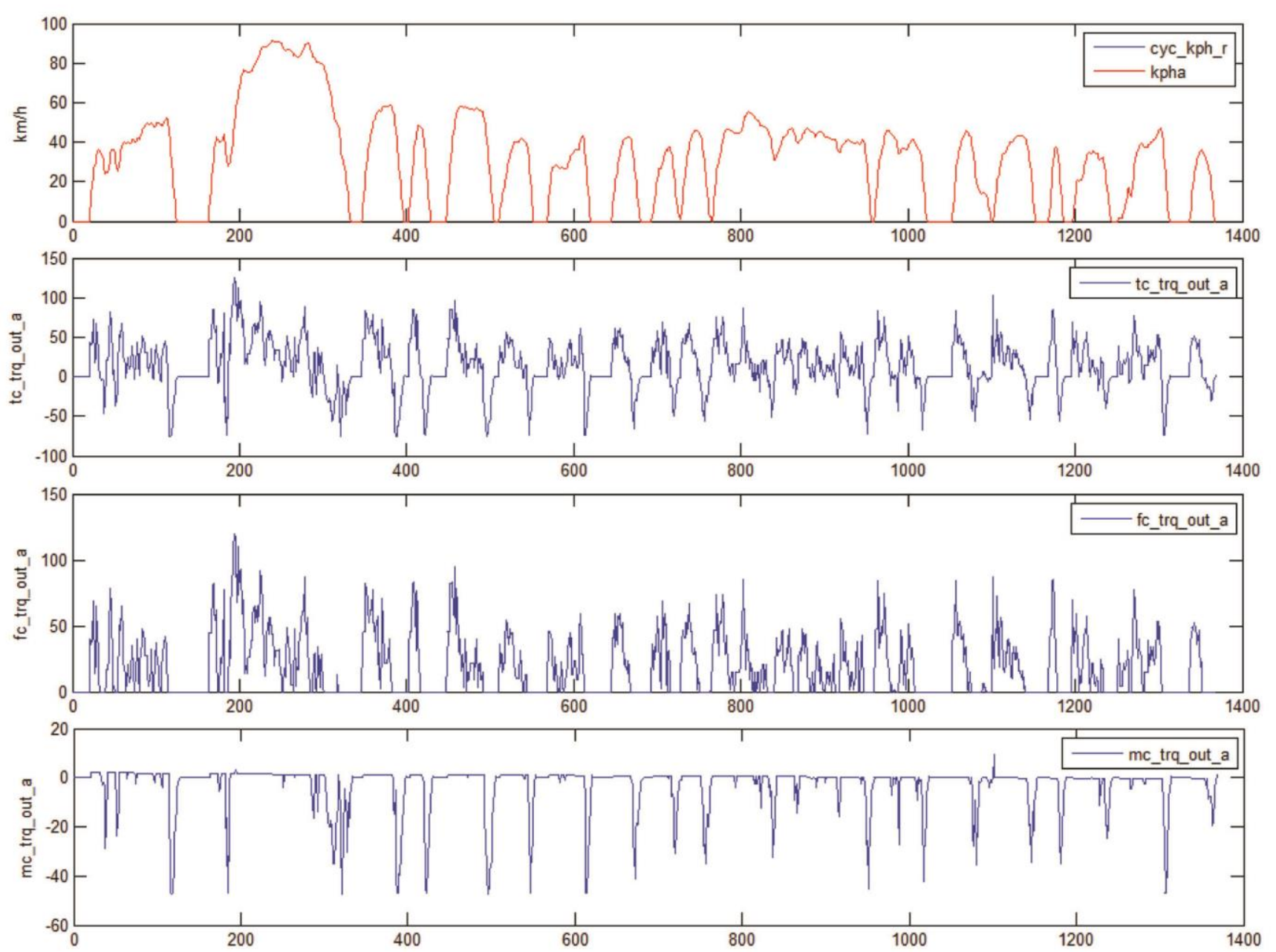

Figure 6. Speed, torque, brake torque and wheel slip of vehicle.

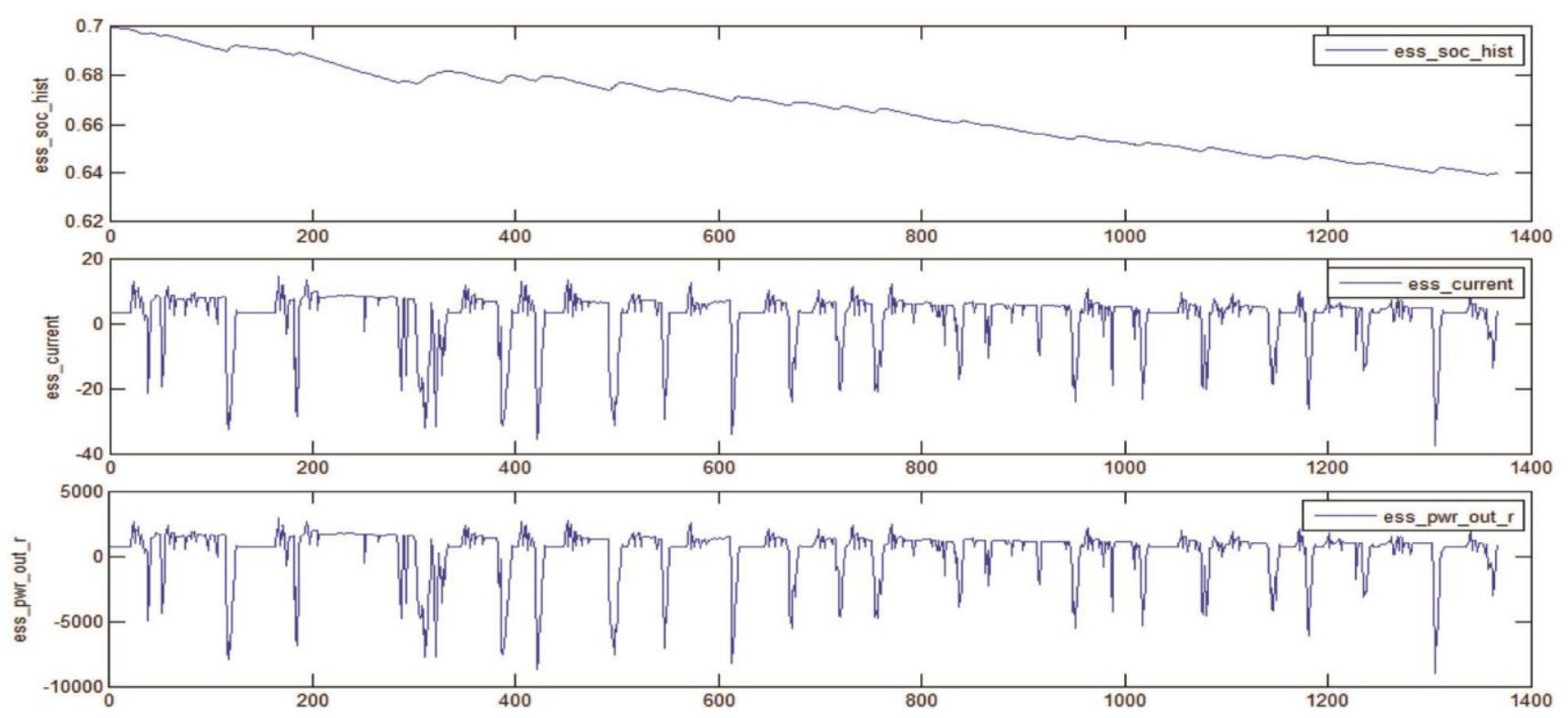

Figure 7. SOC, current and power of energy storage. 

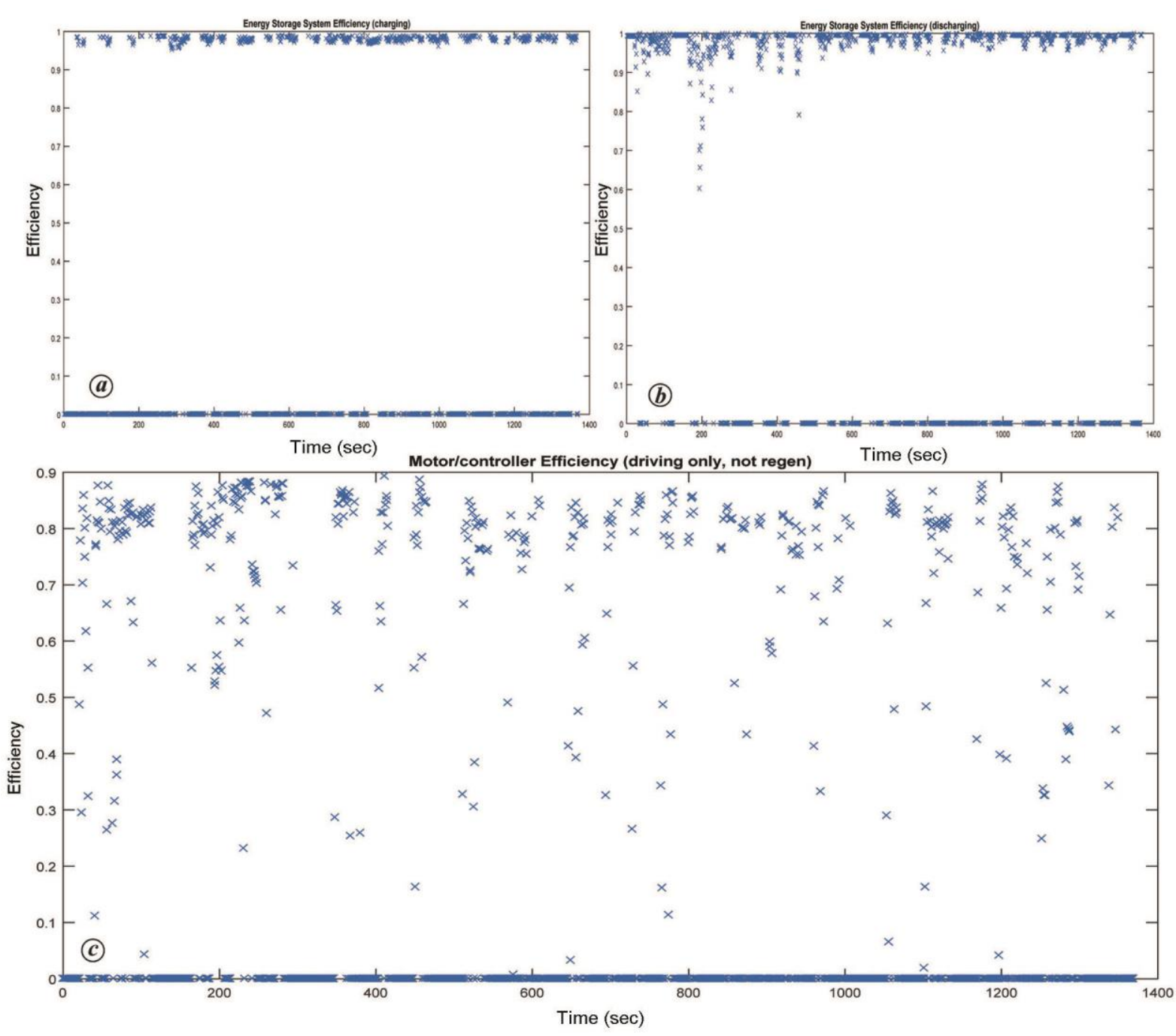

Figure 8. $\boldsymbol{a}$, Energy storage (charging). $\boldsymbol{b}$, Energy storage (discharging). $\boldsymbol{c}$, Efficiency distribution map of motor with controller.

contour map for the motor (with controller) used, the maximum torque capability and motor characteristics mapped on efficiency contour can also be seen in the figure. It is observed that above base speed, efficiency of the motor lies between 0.8 and 0.9 whereas below base speed it is between 0.7 and 0.8 ; however, at lower values of torque it is low for all ranges of speed.

The capability of energy storage device, i.e. lead-acid battery performance has been generated. Supplementary Figures 9 and 10 show voltage, current and power available at different values of SOC.

It can be seen that during charging of energy storage device, the voltage changes from 11.6 to $13 \mathrm{~V}$. Supplementary Figure $9 b$ shows the efficiency at different values of charging current.

Supplementary Figure $10 a$ shows the instantaneous power and pulse power capacity of the energy storage device. Supplementary Figure $10 \mathrm{~b}$ shows the pulse power capability according to depth of discharge; $22.76 \mathrm{kWh}$ of the battery can deliver instantaneous capacity of around
$58 \mathrm{~kW}$ when fully charged. Supplementary Figure $10 \mathrm{~b}$ shows the time for which pulsed power can be drawn, e.g. at DOD of $20 \%$ (SOC of $80 \%$ ) around $54 \mathrm{~kW}$ of power is available for $18 \mathrm{sec}$.

The same input driving cycle (UDDS and WVSUB) used in $\mathrm{CV}$ has been utilized for the analysis. Figures 4 and 5 show the results for UDDS. Figure 4 shows the optimized operating points of the engine on efficiency contours. The efficiency of the engine is distributed with all values mostly above 0.2 (Figure $4 a$ ). The gearbox efficiency is observed to be very high (Figure $4 b$ ).

Figure 5 shows the operating points of engine and motor. It can be seen that at lower values of speed the motor is operated and during mid range of speed the engine is operated. The distribution of operating points at various values of speed and torque is shown in the figure with contours of efficiencies. Whenever the engine is operated with higher than required torque or whenever there is barking, the regenerative energy can be captured by the motor and utilized to charge the battery. The 

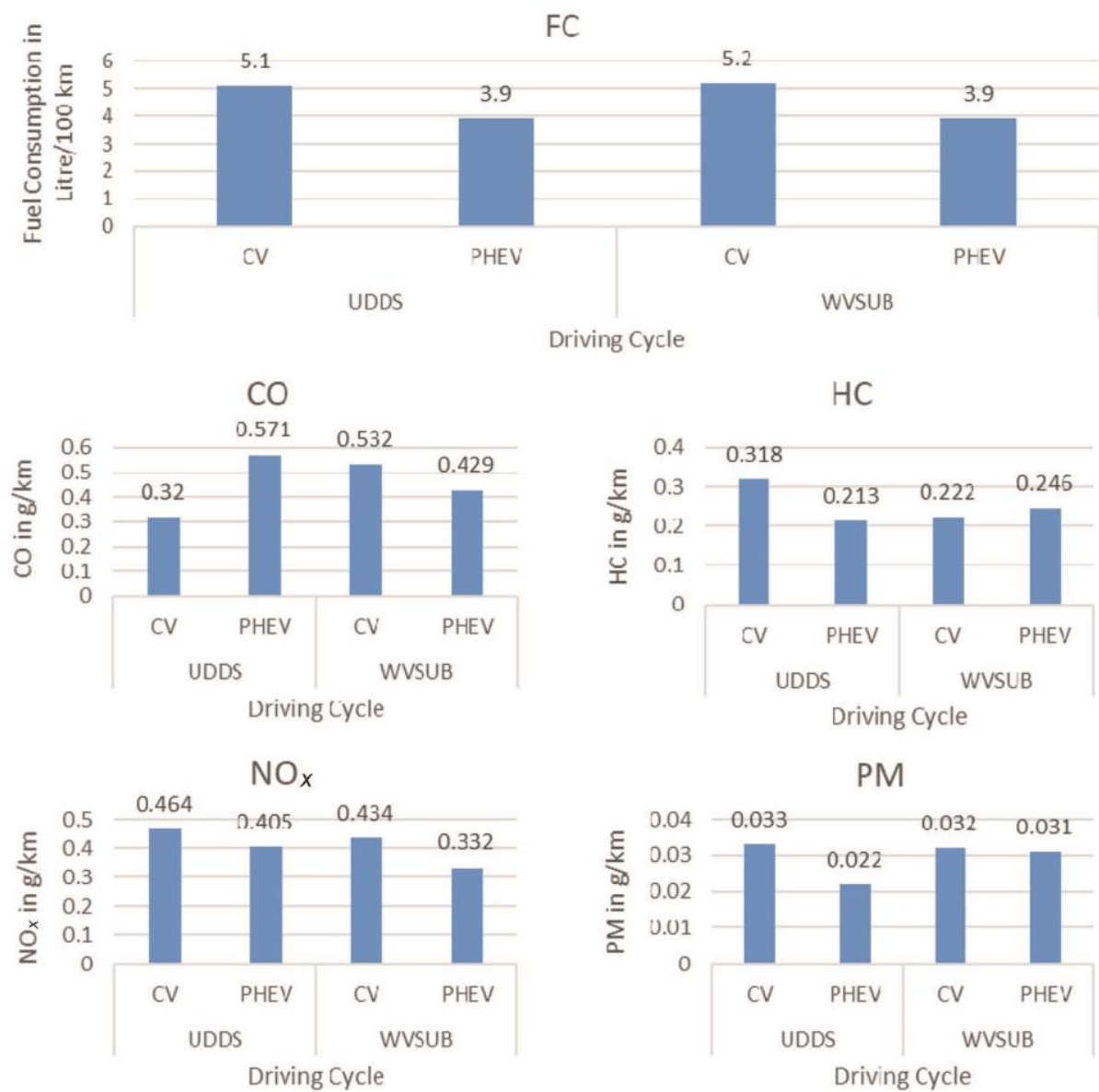

Figure 9. Comparative results of CV and PHEV for UDDS and WVSUB driving cycles.

Table 5. Fuel consumption and emissions - CPHEV

\begin{tabular}{lccccc}
\hline & & \multicolumn{4}{c}{ Emissions $(\mathrm{g} / \mathrm{km})$} \\
\cline { 3 - 6 } Driving cycle & $\begin{array}{c}\text { Fuel consumption } \\
\text { litre/100 km }\end{array}$ & $\mathrm{HC}$ & $\mathrm{CO}$ & $\mathrm{NO}_{x}$ & $\mathrm{PM}$ \\
\hline UDDS & 3.9 & 0.213 & 0.571 & 0.405 & 0.022 \\
WVSUB & 3.9 & 0.246 & 0.429 & 0.332 & 0.031 \\
\hline
\end{tabular}

operating points of regeneration with efficiency can be seen in Figure $5 b$ by negative values (red).

Figure 6 shows the other results generated for speed of the vehicle, torque coupler torque, motor torque and engine torque.

It can be seen that the torque coupler torque is the addition of motor and engine torque. The regenerative torque captured is also shown in Figure $6 a$ by negative values. Figure 7 shows the performance of energy storage battery.

It can be seen that for a distance of $12 \mathrm{~km}$ of travel, SOC of the battery decreases from $70 \%$ to $62 \%$. The corresponding power and current match the motor torque and power requirement values. The negative values of current and power are an indication of charging of the battery or capturing of regenerative energy.
Figure 8 shows the efficiency map of energy storage system charging, discharging and motor-controller.

The energy storage charging and discharging efficiencies are very high. There are some exceptions during discharging, where rapid changes are needed. Motor efficiency is mostly in the range 0.8-0.9; however, lower values are also observed during lower values of speed and torque requirement.

Supplementary Figures 11 and 12 highlight the energy used by each component during normal and braking (regeneration mode) respectively.

It is observed that most of the energy is used by low efficient IC engine followed by rolling resistance and braking. The braking energy can be utilized to generate electric power and charge battery. Supplementary Figure $\underline{12}$ shows energy usage in the regeneration mode. 
Table 5 shows the fuel consumption and emissions for the UDDS and WVSUB driving cycles.

Figure 9 shows the self-explanatory comparative status of the results.

It is observed that $\mathrm{FC}, \mathrm{NO}_{x}$ and $\mathrm{PM}$ are reduced for both driving cycles. The fuel consumption reduces from 5.1 to 3.1 litre $/ 100 \mathrm{~km}$ for UDDS. $\mathrm{NO}_{x}$ value reduces from 0.464 to $0.405 \mathrm{~g} / \mathrm{km}$ and PM value from 0.033 to $0.022 \mathrm{~g} / \mathrm{km}$. The value of $\mathrm{HC}$ reduces from 0.318 to $0.213 \mathrm{~g} / \mathrm{km}$ for UDDS; however, it increases for the WVSUB driving cycle compared to CV (Figure 9). The value of $\mathrm{CO}$ increases from 0.31 to $0.571 \mathrm{~g} / \mathrm{kWh}$ for UDDS, but reduces for the WVSUB driving cycle.

\section{Conclusion}

The performance analysis of $\mathrm{CV}$ and CPHEV has been carried out for USSD and WVUSUB in ADVISORMATLAB combined platform using the same parameters. In-depth analysis with efficiencies and operating points of almost all electrical and mechanical devices has been investigated for torque, power and speed at the input and output of devices. The performance and capability of energy storage devices have been detailed. It is observed that there is $23.52 \%$ fuel saving in CPHEV for the USSD driving cycle and $25 \%$ for WVUSUB compared to CV. $\mathrm{NO}_{x}$ emission decreases by $12.71 \%$ and $23.50 \%$ for the UDDS and WVSUB cycles respectively, compared to CV. PM is reduced by $33.33 \%$ and $3.125 \%$ for UDDS and WVSUB cycles. However, the $\mathrm{HC}$ is reduced by $33.01 \%$ for UDDS but increased by $10.81 \%$ for WVSUB cycle, but $\mathrm{CO}$ is increased by $78.43 \%$ for UDDS and reduced by $19.36 \%$ compared to $\mathrm{CV}$. The results indicate that there is significant reduction in fuel consumption and emissions $\left(\mathrm{NO}_{x}\right.$ and $\left.\mathrm{PM}\right)$ in case of CPHEV compared to CV.

1. Global, E. V., Outlook Clean Energy Ministerial, Electric Vehicle Initiative, International Energy Agency, 2017.

2. Global transportation energy consumption: examination of scenarios to 2040 using ITEDD, US Energy Information Administration, September 2017.

3. http://www.who.int/airpollution/ambient/en/
4. Fuengwarodsakul, N. H., Retrofitting a used car with hybrid electric propulsion system. In Sixth International Conference on Electrical Engineering/Electronics, Computer, Telecommunications and Information Technology, Pattaya, Thailand, 2009.

5. Ghorbani, R., Bibeau, E. and Filizadeh, S., On conversion of hybrid electric vehicles to plug-in. IEEE Trans. Ve. Technol., 2010, 59(4), 2016-2020.

6. Zulkifli, S. A., Saad, N., Syaifuddin, M. and Aziz, R. A., Development of split axle parallel hybrid electric vehicles with in wheel-motor. In IEEE 4th International Conference on Intelligent and Advanced Systems, 2012.

7. Airpocalypse: Assessment of Air Pollution in Indian Cities. Greenpeace Environment Trust, 2017.

8. Guptea, S., Experimental analysis and feasibility study of $1400 \mathrm{cc}$ diesel engine car converted into hybrid electric vehicle by using BLDC hub motors. Energy Procedia, 2014, 54.

9. Guttikunda, S. K. and Mohan, D., Re-fueling road transport for better air quality in India. Energy Policy, 2014, 68.

10. Jenkins, S. and Ferdowsi, M., HEV to PHEV conversion compatibility. In IEEE Vehicle Power and Propulsion Conference, Harbin, China, 2008

11. Jenkins, S. and Ferdowsi, M., Urban bus fleet conversion to hybrid fuel cell optimal power trains (EWGT2013). ProcediaSoc. Behav. Sci., 2014, 111, 692-701.

12. Lal, D. K., Barisal, A. K. and Tripathy, M., Grey wolf optimizer algorithm based fuzzy PID controller for AGC of multi-area power system with TCPS. Procedia Comput. Sci., 2016, 92, 99-105.

13. Mallick, R. K. and Nahak, N., Grey wolves-based optimization technique for tuning damping controller parameters of unified power flow controller. In International Conference on Electrical, Electronics, and Optimization Techniques, Chennai, 2016.

14. Mallick, R. K., Haque, F., Rout, R. R. and Debnath, M. K., Application of grey wolves-based optimization technique in multi-area automatic generation control. International Conference on Electrical, Electronics and Optimization Techniques, Chennai, India, 2016.

15. McIntyre, M. L., Maegan, Y. and Kessigner, R., Plug-in hybrid conversion: as a capstone project and research test bed. In IEEE International Electric Vehicle Conference, Greenville, SC, USA, 2012.

16. Advance Vehicle Simulator Software/FC_C167_emis.m.

17. Gujarathi, P. K., Shah, V. A. and Lokhande, M. M., Design, modeling, simulation and analysis for conversion of conventional Tata Indica car into plug - in hybrid electric vehicle. In 28th International Electric Vehicle Symposium and Exhibition, KINTEX, Korea, 2015.

Received 7 March 2018; revised accepted 21 May 2019

doi: $10.18520 / \mathrm{cs} / \mathrm{v} 119 / \mathrm{i} 7 / 1123-1130$ 